\title{
Proton motive force underpins respiration-mediated potentiation of aminoglycoside lethality in pathogenic Escherichia coli
}

\author{
Calum M. Webster ${ }^{1} \cdot$ Ayrianna M. Woody $^{1} \cdot$ Safura Fusseini $^{1} \cdot$ Louis G. Holmes $^{1} \cdot$ Gary K. Robinson $^{1}$. \\ Mark Shepherd ${ }^{1}$ iD
}

Received: 19 July 2021 / Revised: 2 November 2021 / Accepted: 15 November 2021 / Published online: 6 January 2022

(c) The Author(s) 2022

\begin{abstract}
It is well known that loss of aerobic respiration in Gram-negative bacteria can diminish the efficacy of a variety of bactericidal antibiotics, which has lead to subsequent demonstrations that the formation of reactive oxygen species (ROS) and the proton motive force (PMF) can both play a role in antibiotic toxicity. The susceptibility of Gram-negative bacteria to aminoglycoside antibiotics, particularly gentamicin, has previously been linked to both the production of ROS and the rate of antibiotic uptake that is mediated by the PMF, although the relative contributions of ROS and PMF to aminoglycoside toxicity has remained poorly understood. Herein, gentamicin was shown to elicit a very modest increase in ROS levels in an aerobically grown Escherichia coli clinical isolate. The well-characterised uncoupler 2,4-dinitrophenol (DNP) was used to disrupt the PMF, which resulted in a significant decrease in gentamicin lethality towards E. coli. DNP did not significantly alter respiratory oxygen consumption, supporting the hypothesis that this uncoupler does not increase ROS production via elevated respiratory oxidase activity. These observations support the hypothesis that maintenance of PMF rather than induction of ROS production underpins the mechanism for how the respiratory chain potentiates the toxicity of aminoglycosides. This was further supported by the demonstration that the uncoupler DNP elicits a dramatic decrease in gentamicin lethality under anaerobic conditions. Together, these data strongly suggest that maintenance of the PMF is the dominant mechanism for the respiratory chain in potentiating the toxic effects of aminoglycosides.
\end{abstract}

Keywords Aminoglycoside $\cdot$ Escherichia coli $\cdot$ Nitric oxide

\section{Introduction}

It is well known that the abolition of aerobic respiration dramatically reduces the toxic effects of bactericidal antibiotics ((Lobritz et al. 2015); reviewed in (Stokes et al. 2019)). It is also accepted that the lethality of bactericidal antibiotics is linked to the activation of pathways that result in oxidative damage via elevation of aerobic respiratory rates (Dwyer et al. 2007, 2014; Foti et al. 2012), with superoxide causing destabilisation of iron-sulphur complexes (Imlay and Fridovich 1991; Keyer and Imlay 1996) leading to iron dysregulation and elevated Fenton chemistry. While different

Communicated by Reinhard Krämer.

Mark Shepherd

M.Shepherd@kent.ac.uk

1 School of Biosciences, RAPID Group, University of Kent, Canterbury CT2 7NJ, UK classes of bactericidal antibiotics have different primary cellular targets, most are able to induce the formation of hydroxyl radicals which is thought to be linked to the aerobic respiratory chain (Kohanski et al. 2007, 2010). The bactericidal aminoglycoside gentamicin directly targets the 30S subunit of the ribosome leading to protein mistranslation with the toxicity believed to be due to either irreversible uptake leading to complete ribosome inhibition (Davis 1987) or insertion of mis-translated proteins into the inner membrane (Davis et al. 1986). Evidence has suggested that mistranslated proteins brought to the membrane activate the two-component stress-response sensor $\mathrm{Cpx}$ which then may also activate ArcA a redox-responsive two-component transcription factor leading to respiratory and metabolic changes (Kohanski et al. 2008). These changes are proposed to lead to oxidative stress, production of hydroxyl radicals and cell death (Kohanski et al. 2008). However, for aminoglycosides, such as gentamicin, there is strong evidence for a link between antibiotic uptake provided by the PMF 
(Taber et al. 1987) and toxicity that is independent of ROS formation. It is suggested that $\Delta \psi$, the electrical component of the PMF, provides the main driving force for the uptake of positively charged aminoglycosides (Taber et al. 1987; Farha et al. 2013). Indeed, aminoglycoside uptake has been shown to be related to $\Delta \psi$ in E. coli, Staphylococcus aureus and Bacillus subtilis (Taber et al. 1987).

There are a number of well-characterised uncouplers of the bacterial PMF, such as 2,4-dinitrophenol (DNP) and carbonyl cyanide $m$-chloromethoxyphenyl hydrazone (CCCP) (Lewis et al. 1994). DNP acts as a proton ionophore providing a path to transport protons across the membrane uncoupling the PMF (Gage and Neidhardt 1993). Dissipation of the electrical component of the PMF in E. coli K-12 using DNP has been shown to inhibit dihydrostreptomycin uptake and susceptibility (Campbell and Kadner 1980). The respiratory inhibitor nitric oxide (NO) provides resistance to gentamicin in pathogenic E. coli (Ribeiro et al. 2021) and Salmonella enterica (McCollister et al. 2011), and the latter study attributed an observed decrease in gentamicin uptake resulted from NO-mediated inhibition of the terminal oxidase complexes of the respiratory chain (McCollister et al. 2011). While there is considerable evidence in separate studies to implicate both the maintenance of PMF and ROS production by the respiratory chain as potentiators of aminoglycoside lethality, there is a notable lack of comparative studies where the two mechanisms are assessed side by side. Hence, the current work sought to assess how the interplay between ROS, PMF and respiratory activity affects the lethality of gentamicin.

\section{Materials and methods}

\section{Bacterial isolates}

EC958 is a well-characterised E. coli O25: H4-ST131 multidrug-resistant urosepsis-causing strain that is globally disseminated and resistant to multiple classes of antibiotics (Nicolas-Chanoine et al. 2008; Croxall et al. 2011; Totsika et al. 2011; Forde et al. 2014).

\section{Aerobic growth conditions}

E. coli EC958 ST131 wild type was grown in $10 \mathrm{~mL} \mathrm{LB}$ in a $50 \mathrm{~mL}$ falcon tube at $37{ }^{\circ} \mathrm{C}$ and $180 \mathrm{rpm}$ overnight to stationary phase. The stationary phase cultures were used to inoculate (at $1 \% \mathrm{v} / \mathrm{v}$ ) M9 minimal medium ( $16 \mathrm{~g} / \mathrm{L}$ $\mathrm{Na}_{2} \mathrm{HPO}_{4} \cdot 2 \mathrm{H}_{2} \mathrm{O}, 3 \mathrm{~g} / \mathrm{L} \mathrm{KH}_{2} \mathrm{PO}_{4}, 0.5 \mathrm{~g} / \mathrm{L} \mathrm{NaCl}, 1 \mathrm{~g} / \mathrm{L} \mathrm{NH}_{4} \mathrm{Cl}$, $0.24 \mathrm{~g} / \mathrm{L} \mathrm{MgSO}_{4}, 0.01 \mathrm{~g} / \mathrm{L} \mathrm{CaCl}_{2}$, and $4 \mathrm{~g} / \mathrm{L}$ glucose) supplemented with $0.1 \%$ casamino acids (w/v). Cultures were incubated at $37^{\circ} \mathrm{C}$ and $180 \mathrm{rpm}$ until mid-exponential phase before use in the following experiments.

\section{Catalase assay}

E. coli EC958 ST131 wild-type cultures were grown using the aerobic growth conditions splitting at mid-exponential phase (approx $1.6 \times 10^{8}$ cells $/ \mathrm{mL}$ ) into $60 \mathrm{~mL}$ suspensions in $250 \mathrm{~mL}$ conical flasks. These suspensions were exposed to DNP $(0$ or $1 \mathrm{mM})$, hydrogen peroxide $(0.1 \mathrm{mM})$ or varying concentrations of gentamicin for $30 \mathrm{~min}$ at $37{ }^{\circ} \mathrm{C}$. Cell suspensions were harvested $(5000 \mathrm{x} g$ for $5 \mathrm{~min}$ at $4{ }^{\circ} \mathrm{C}$ ) and washed in $50 \mathrm{mM}$ Potassium Phosphate buffer a total of 3 times before sonication at $18,000 \mathrm{~Hz}$ for $5 \times 30 \mathrm{~s}$ intervals with $30 \mathrm{~s}$ incubation on ice in between. Cell debris was removed via centrifugation at 15,000 rpm for $20 \mathrm{~min}$ at $4{ }^{\circ} \mathrm{C}$. For the catalase assay, $50 \mu \mathrm{L}$ of cell-free supernatant was added to $950 \mu \mathrm{L}$ of $0.036 \%$ (w/w) $\mathrm{H}_{2} \mathrm{O}_{2}$ in a quartz cuvette and the linear decrease in absorbance at $240 \mathrm{~nm}$ was measured that corresponded to consumption of $\mathrm{H}_{2} \mathrm{O}_{2}$. Conversion of $\Delta \mathrm{A} 240 \mathrm{~min}^{-1}$ to $(\mu$ moles $\mathrm{H}_{2} \mathrm{O}_{2}$ ) min $^{-1}$ was achieved using the extinction coefficient $\varepsilon_{240}=36 \mathrm{M}^{-1} \mathrm{~cm}^{-1}$ (Anderson et al. 1995). A Markwell assay (Markwell et al. 1978) was used to determine protein concentrations to convert units to $\mu$ moles $\mathrm{H}_{2} \mathrm{O}_{2} \min ^{-1}(\mathrm{mg}$ protein $)^{-1}$. Three biological repeats were carried out for each condition with three technical repeats completed for each biological repeat.

\section{Native-PAGE KatE and KatG catalase assay}

The same E. coli EC958 ST131 wild-type cell extract samples used for the catalase assay exposed to $0 \mu \mathrm{g} / \mathrm{mL}$ gentamicin, $100 \mu \mathrm{g} / \mathrm{mL}$ gentamicin or $0.1 \mathrm{mM} \mathrm{H}_{2} \mathrm{O}_{2}$ were also used for the Native-PAGE (polyacrylamide gel electrophoresis) $K a t E$ and $K a t G$ assay. Native-PAGE gels used composed of $5 \%$ stacking and $6 \%$ resolving acrylamide gels. The exact gel components, loading sample buffer and running buffer used are as described in (Pezzoni et al. 2018). A Markwell assay (Markwell et al. 1978) was used to determine protein concentrations with $10 \mu \mathrm{g}$ of cell extract loaded into each lane. For the positive control, 10 units $(0.26 \mathrm{ng})$ of bovine catalase were used (one unit of catalase will decompose $1 \mu$ mole of $\mathrm{H}_{2} \mathrm{O}_{2}$ per minute at $\mathrm{pH} 7.0$ at $25^{\circ} \mathrm{C}$ ). A Bio-RAD Mini-PROTEAN Tetra Cell was used to run two identical gels at $15 \mathrm{~mA}$ for $2 \mathrm{~h}$ $45 \mathrm{~min}$ at $4{ }^{\circ} \mathrm{C}$. One gel was stained with Coomassie stain (1 g/L Coomassie Brilliant blue R, 40\% methanol, 10\% acetic acid and $50 \% \mathrm{ddH}_{2} \mathrm{O}$ ) overnight before applying de-stain $\left(40 \%\right.$ methanol, $10 \%$ acetic acid and $\left.50 \% \mathrm{ddH}_{2} \mathrm{O}\right)$ and then imaging use a G-box gel doc system. The second identical gel was stained for catalase activity. This gel was soaked in distilled water for $5 \mathrm{~min}$ before incubating with $100 \mathrm{~mL} 4 \mathrm{mM} \mathrm{H}_{2} \mathrm{O}_{2}$ for $10 \mathrm{~min}$ at room temperature. 
After $\mathrm{H}_{2} \mathrm{O}_{2}$ incubation, the gel was washed with distilled water before soaking in a $100 \mathrm{~mL}$ solution containing $1 \%$ (w/v) ferric chloride and $1 \%(\mathrm{w} / \mathrm{v})$ potassium ferricyanide (III) at room temperature. As soon as the gel turned dark green ( $\sim \mathrm{min})$, the ferric chloride and potassium ferricyanide solutions were removed and the gel rinsed with distilled water before imaging. ImageJ v1.53 was used to analyze the band intensities of the KatE/G bands. The native PAGE gel image was converted to a TIF (8-bit) (greyscale) with each lane seperated into an equal strip and a profile plot generated for each. The areas of the KatE/G peaks were determined from the profile plots and reported as band intensity.

\section{ROS flow cytometer assay}

E. coli EC958 ST131 wild-type cultures were grown using the aerobic growth conditions to mid-exponential phase when suspensions of $10^{8}$ cells $/ \mathrm{mL}$ were prepared in fresh M9 minimal medium supplemented with $0.1 \%$ casamino acids (w/v). These suspensions were incubated at $37{ }^{\circ} \mathrm{C}$ for $30 \mathrm{~min}$ and then mixed with $1 \mathrm{X}$ ROS dye (Thermo Fisher Total Reactive Oxygen Species Assay Kit $520 \mathrm{~nm}-$ catalog number $=88-5930-74$ ), a DCFDA analogue-based dye that is well-suited for detection of free radical containing ROS such as superoxide. Aliquots $(200 \mu \mathrm{L})$ of the ROS-dyed suspension were added to a foil covered Greiner Bio-One 96-well, F-bottom (chimney well) microplate. Microplates were incubated at $37^{\circ} \mathrm{C}$ for $30 \mathrm{~min}$ before exposing to gentamicin $(100 \mu \mathrm{g} / \mathrm{mL})$, milliQ water (for no treatment negative control sample) or $1 \mathrm{mM} \mathrm{H}_{2} \mathrm{O}_{2}$ (positive control). A $20 \mu \mathrm{L}$ sample was taken at 30 and $90 \mathrm{~min}$ after exposure. Samples were diluted 1:10 in Phosphate-Buffered Saline (PBS) and fixed with DAPI $(5 \mu \mathrm{g} / \mathrm{mL})$ in $4 \%$ PFA (paraformaldehyde)-PBS solution. A BD FACSJAZZ ${ }^{\mathrm{TM}}$ flow cytometer was used to analyse the fixed samples capturing 100,000 events for each sample. DAPI was excited by a $405 \mathrm{~nm}$ laser and detected with a 450/50 nm band-pass emission filter. ROS dye was excited by a $488 \mathrm{~nm}$ laser and detected by a 513/17 nm band-pass emission filter. A two-gate system partially adapted from (McBee et al. 2017) was used to analyse the samples (Supplemental Data, Fig. S1) using NovoExpress 1.3.0 software. The first gate used FSC (Forward Scatter) against FSC-Width to determine single cells, removing doublets and debris. All events that passed the first gate were then screened by the second DAPI gate to identify intact cells (DAPI binds to DNA). Fluorescent intensity of the ROS dye was then measured in all cells that passed the DAPI gate (minimum of $60,000)$ and mean values reported.

\section{DNP gentamicin susceptibility assays}

For survivability assays under aerobic conditions, E. coli EC958 ST131 wild-type cultures were grown using the aerobic growth conditions to mid-exponential phase when suspensions of $10^{8}$ cells $/ \mathrm{mL}$ were prepared in fresh M9 minimal medium supplemented with $0.1 \%$ casamino acids $(\mathrm{w} / \mathrm{v})$. These suspensions were exposed to DNP $(0$ or $1 \mathrm{mM})$ for $30 \mathrm{~min}$ at $37{ }^{\circ} \mathrm{C}$ before incubation with various concentrations of gentamicin for $90 \mathrm{~min}$. After gentamicin exposure, serial dilutions were carried out in 1X PBS and cells were spotted on LB agar in triplicate for overnight incubation at $37^{\circ} \mathrm{C}$ for colony counting the next day. Six repeats including two biological repeats were performed for each condition.

For survivability assays under anaerobic conditions, $E$. coli EC958 was grown in $10 \mathrm{~mL}$ M9 minimal media supplemented with $0.1 \%$ casamino acids ( $\mathrm{w} / \mathrm{v}), 100 \mathrm{mM}$ sodium nitrate and $0.2 \%$ glycerol $(\mathrm{v} / \mathrm{v})$ in a $50 \mathrm{~mL}$ falcon tube at $37^{\circ} \mathrm{C}$ and $180 \mathrm{rpm}$ aerobially overnight to stationary phase. The stationary phase cultures were used to inoculate $(1 \%$ v/v) $30 \mathrm{~mL}$ of M9 minimal media supplemented with $0.1 \%$ casamino acids (w/v), $100 \mathrm{mM}$ sodium nitrate and $0.2 \%$ glycerol (v/v) in sealed serum bottles. Cultures were then sparged with nitrogen gas for $3 \mathrm{~min}$ each before incubation in a static incubator at $37^{\circ} \mathrm{C}$ to until mid-exponential phase. Cultures were then diluted to $10^{8}$ cells $/ \mathrm{mL}$ in serum bottles and pre-exposed to $\pm 1 \mathrm{mM}$ DNP for $30 \mathrm{~min}$ before incubation with varying concentrations of gentamicin for $90 \mathrm{~min}$ at $37{ }^{\circ} \mathrm{C}$ in a static incubator. Cultures were re-sparged with nitrogen gas for 1.5 min both after DNP and gentamicin addition to maintain anaerobic conditions. After gentamicin exposure, serial dilutions were carried out in 1X PBS and cells were spotted on LB agar in triplicate for overnight incubation at $37{ }^{\circ} \mathrm{C}$ for colony counting the next day. Six repeats including two biological repeats were performed for each condition.

\section{Assay of the membrane electrical potential}

E. coli EC958 ST131 wild-type cultures were grown using the aerobic growth conditions to mid-exponential phase when suspensions of $10^{8}$ cells $/ \mathrm{mL}$ were prepared in fresh M9 minimal medium supplemented with $0.1 \%$ casamino acids (w/v). These suspensions were exposed to DNP ( 0 or $1 \mathrm{mM}$ ) or GSNO (0 or $15 \mathrm{mM})$ for $30 \mathrm{~min}$ at $37^{\circ} \mathrm{C}$. Cells were harvested (4500 $\mathrm{xg}$ for $3 \mathrm{~min}$ ) and washed in $5 \mathrm{mM}$ HEPES buffer $\mathrm{pH} 7.2$ containing $5 \mathrm{mM}$ glucose a total of 3 times. The reaction buffer was added to a Greiner Bio-One 96-well, F-bottom (chimney well), black, fluotrac, medium binding microplate so that the final concentration of the reaction buffer components after addition of cells is $5 \mathrm{mM}$ HEPES buffer, pH 7.2 with $5 \mathrm{mM}$ glucose, $100 \mathrm{mM} \mathrm{KCl}$ and $2 \mu \mathrm{M}$ of DISC 3 . The fluorescence was monitored on a 
FLUOstar Omega plate reader for $60 \mathrm{~s}$ at $30 \mathrm{~s}$ intervals using excitation and emission wavelengths of $584 \mathrm{~nm}$ and $655 \mathrm{~nm}$, respectively, to gather a baseline. Cells were then added at a final concentration to $4 \times 10^{7}$ cells $/ \mathrm{mL}$ in volume $200 \mu \mathrm{l}$. Fluorescence was then monitored for a total of $45 \mathrm{~min}$ at $30 \mathrm{~s}$ intervals. $200 \mu \mathrm{l}$ of $5 \mathrm{mM}$ HEPES buffer with $5 \mathrm{mM}$ glucose was used for the negative controls.

\section{Oxygen consumption assay for DNP}

E. coli EC958 ST131 wild-type cultures were grown using the aerobic growth conditions to mid-exponential phase when cells were harvested (5000 xg for $5 \mathrm{~min}$ ) and re-suspended in fresh M9 minimal media supplemented with $0.1 \%$ casamino acids (w/v). A Rank Brothers oxygen electrode was baselined using $4 \mathrm{~mL}$ of distilled water and calibrated with sodium dithionite essentially as previously described (Gilberthorpe and Poole 2008) using the following parameters: polarizing volts $=0.6$, stirring to setting $6,37^{\circ} \mathrm{C}$. Voltage data were then recorded until a reading of $0 \mathrm{~V}$ was reached. The concentration of oxygen for the air-saturated growth media was $200 \mu \mathrm{M}$ as previously used (Gilberthorpe and Poole 2008; Shepherd et al. 2010). $3.6 \mathrm{~mL}$ of M9 minimal medium supplemented with $0.1 \%$ casamino acids (w/v) was added to the chamber and the baseline voltage was recorded for $5 \mathrm{~min}$ before cells were added to a final concentration of $8 \times 10^{7}$ cells $/ \mathrm{mL}$. Voltage data were gathered for $8 \mathrm{~min}$ before the plunger was inserted to eliminate external oxygen for $10 \mathrm{~min}$ prior to addition of $1 \mathrm{mM} \mathrm{DNP}$ or ethanol $(5 \% \mathrm{v} / \mathrm{v})$ for the negative control.

\section{Oxygen Consumption assay for FCCP}

An oxygen consumption assay was carried out on E. coli EC958 ST131 wild-type cultures using $10 \mu \mathrm{M}$ carbonyl cyanide- $p$-trifluoromethoxyphenylhydrazone (FCCP). The assay was the same as for DNP apart from a $2 \mathrm{~mL}$ final volume being used instead of $4 \mathrm{~mL}$ in the electrode due to limited FCCP being available.

\section{Anaerobic growth conditions}

E. coli EC958 was grown in $10 \mathrm{~mL}$ M9 minimal media supplemented with $0.1 \%$ casamino acids (w/v), $0.2 \%$ glycerol $(\mathrm{v} / \mathrm{v})$ and $\pm 100 \mathrm{mM}$ sodium nitrate (to provide the exogenous electron acceptor) in a $50 \mathrm{~mL}$ falcon tube at $37{ }^{\circ} \mathrm{C}$ and $180 \mathrm{rpm}$ aerobially overnight to stationary phase. The stationary phase cultures were used to inoculate $(0.2 \% \mathrm{v} / \mathrm{v})$ $30 \mathrm{~mL}$ of M9 minimal media supplemented with $0.1 \%$ casamino acids (w/v), $0.2 \%$ glycerol (v/v) and $\pm 100 \mathrm{mM}$ sodium nitrate in sealed serum bottles. Cultures were then sparged with nitrogen gas for $3 \mathrm{~min}$ and incubated at $37^{\circ} \mathrm{C}$ in a static incubator. Samples $(1 \mathrm{~mL})$ from 3 biological repeats were taken every hour for $8 \mathrm{~h}$ and then again after $24 \mathrm{~h}$ and $\mathrm{OD}_{600}$ was measured on a Cary $60 \mathrm{UV}-\mathrm{Vis}$ spectrophotometer (Agilent Technologies).

\section{Results}

\section{Gentamicin elicits a small increase in ROS in aerobically-grown $E$. coli}

Previous studies have reported that gentamicin leads to increased ROS levels in nonpathogenic $E$. coli with $\mathrm{H}_{2} \mathrm{O}_{2}$ being the most notable increase, although these statistically significant increases were marginal and drastically lower than for other antibiotics (Dwyer et al. 2014). Hence, it was of interest to quantify gentamicin-mediated increases in ROS in the multidrug-resistant $E$. coli clinical isolate, with a particular focus on $\mathrm{H}_{2} \mathrm{O}_{2}$. The first approach was an indirect measure using a catalase assay to measure the catalase activity in the cytosol ( $K a t E$ and $K a t G$ ) by the decomposition of $\mathrm{H}_{2} \mathrm{O}_{2}$ (Fig. 1A): if elevated peroxide is present then these cells will express higher levels of catalase. Catalase-peroxidase hydroperoxidases I (KatG) and II (KatE) are both known to be located in the cytoplasm (Hillar et al. 1999; Kumar and Imlay 2013). NADH peroxidase ( $a h p C F)$ can also scavenge $\mathrm{H}_{2} \mathrm{O}_{2}$ and is located in the cytoplasm (Kumar and Imlay 2013). To account for the known effects of gentamicin on protein translation, a markwell assay was first conducted to allow the catalase assay results to be adjusted to the total protein present in the cell extract. The total protein level in the cell extract was lower for the $100 \mu \mathrm{g} /$ $\mathrm{mL}$ gentamicin-exposed sample (58\% of the the $0 \mu \mathrm{g} / \mathrm{mL}$ gentamicin-exposed sample). One-way ANOVA results showed there was a significant difference between the three treatment groups of the the catalase assay $(F(2,24)=88.34$, $P<0.0001$ ) (Fig. 1A). As a positive control, exposure to $\mathrm{H}_{2} \mathrm{O}_{2}(0.1 \mathrm{mM})$ was shown to result in a fourfold increase in catalase activity compared to the $0 \mu \mathrm{g} / \mathrm{mL}$ gentamicin sample (Tukey's post hoc test $P<0.0001$ ). However, on addition of $100 \mu \mathrm{g} / \mathrm{mL}$ gentamicin, only a small increase in catalase activity was observed that is not statistically significant (Tukey's post hoc test $P=0.3117$ ). As an alternative approach to measure gentamicin-mediated ROS generation, a 2',7'-dichlorodihydrofluorescein diacetate-based fluorescent dye was used to directly measure the ROS present in a flow cytometer. A small increase in ROS production can be seen at both $30 \mathrm{~min}$ and $90 \mathrm{~min}$ after the addition of $100 \mu \mathrm{g} / \mathrm{mL}$ gentamicin (Fig. 1B) compared to the negative control sample $\left(+\right.$ milliQ $\left.\mathrm{H}_{2} \mathrm{O}\right)$. A native PAGE gel catalase assay using the cell extract from (Fig. 1A) was then carried out as a more direct method of measuring the KatE and KatG expression levels (Fig. 1C+D). Cell extract from E.coli exposed as in Fig. 1A to $0 \mu \mathrm{g} / \mathrm{mL}$ gentamicin, $0.1 \mathrm{mM}$ 

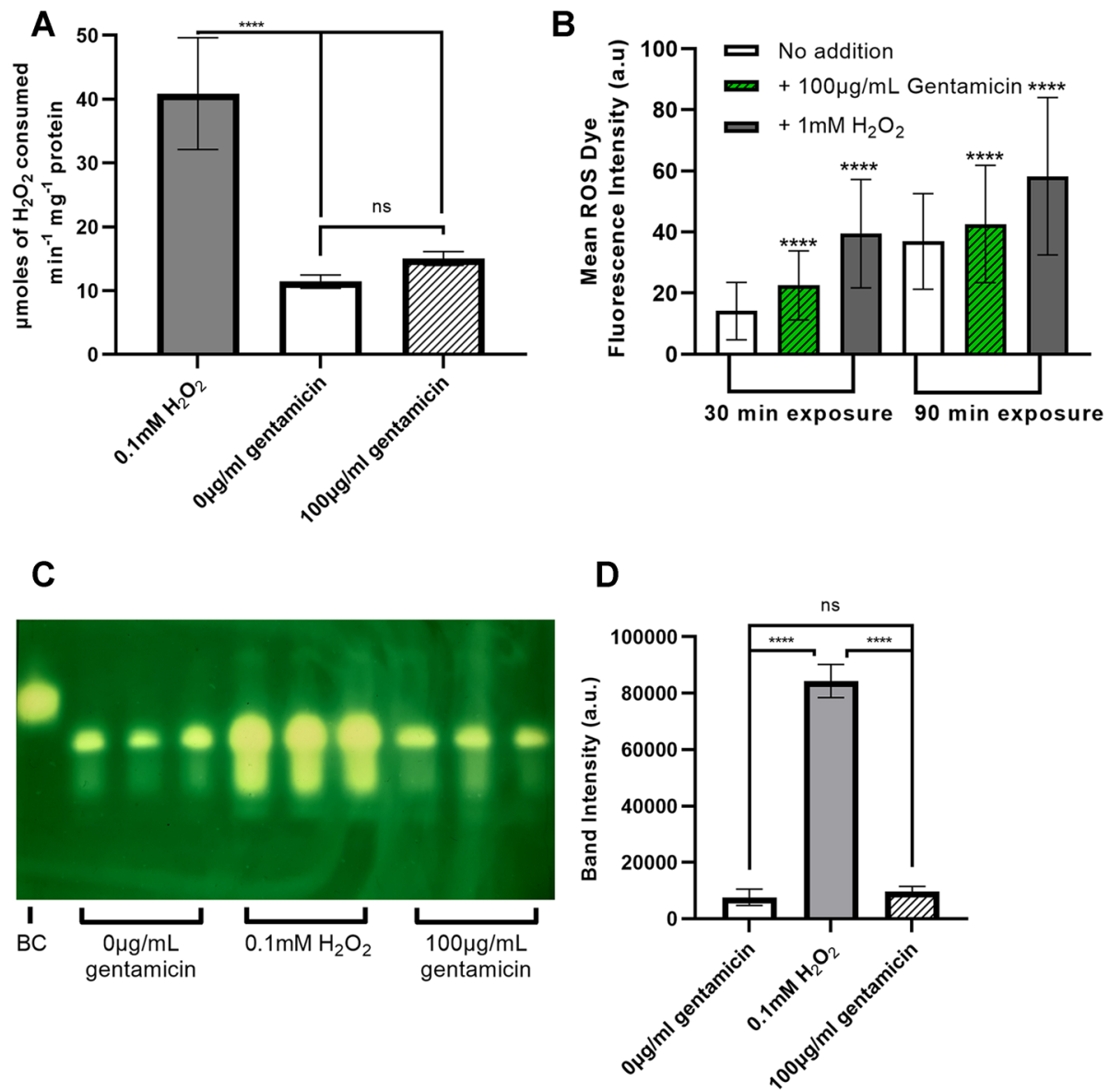

Fig. 1 Gentamicin elicits a minimal increase in reactive oxygen species in aerobically grown $E$. coli. A Suspensions of $1.6 \times 10^{8}$ cells $/ \mathrm{ml}$ of $E$. coli EC958 grown in M9 minimal medium supplemented with $0.1 \%$ casamino acids were exposed to a sub-lethal level of hydrogen peroxide $(0.1 \mathrm{mM}), 0 \mu \mathrm{g} / \mathrm{mL}$ gentamicin or $100 \mu \mathrm{g} / \mathrm{ml}$ gentamicin for $30 \mathrm{~min}$ with three biological repeats each with three technical repeats completed for each. Cells were then washed, sonicated, cell debris was removed and catalase activity was measured in the cellfree extract (One-way ANOVA with Tukey's post hoc tests: ****P value $<0.0001$, n.s (not significant): $P$ value $>0.05$ ). B A fluorescent sensitive dye was used to detect ROS in aerobically growing $E$. coli EC958 using a BD FACSJAZZTM flow cytometer. Whole cells were selected using DAPI staining and gentamicin-mediated changes in

$\mathrm{H}_{2} \mathrm{O}_{2}$ or $100 \mu \mathrm{g} / \mathrm{mL}$ gentamicin was run on a native PAGE gel before incubating the gel with $\mathrm{H}_{2} \mathrm{O}_{2}$ and then stained by a ferric chloride-potassioum ferricyanide (III) solution. Potassium ferricyanide (III) reacts with $\mathrm{H}_{2} \mathrm{O}_{2}$ being reduced to potassium ferrricyanide (II). Ferric chloride then reacts with potassium ferrricyanide (II) to form a blue/green insoluble precipitate. This reaction does not happen where KatE and KatG have decomposed the $\mathrm{H}_{2} \mathrm{O}_{2}$ leaving a white band proportional in size to KatE and KatG activity. For a loading control, an additional identical native PAGE gel was run and stained with Coomassie blue which displayed identical loading of each cell extract sample (Supplemental Data, Fig.

fluorescence were analysed using fluorescent intensity of the ROS dye. At least 60,000 cells were sampled for each condition with mean values displayed. (****One-way ANOVA with Tukey's post hoc tests: $P$ value $<0.0001)$. C Native PAGE catalase activity gel. E. coli EC958 cells exposed and extract prepared as in A. $10 \mu \mathrm{g}$ of each cell extract was loaded from cells exposed to hydrogen peroxide $(0.1 \mathrm{mM}), 0 \mu \mathrm{g} / \mathrm{mL}$ gentamicin or $100 \mu \mathrm{g} / \mathrm{ml}$ gentamicin. 10 units of bovine catalase (BC) loaded as a positive control. Gel exposed to $4 \mathrm{mM} \mathrm{HO}_{2}$ before staining with ferric chloride-potassium ferricyanide solution. D ImageJ analysis of band intensities conducted on the KatE/KatG activity bands (One-way ANOVA with Tukey's post hoc tests: $* * * * P$ value $<0.0001$, n.s (not significant): $P$ value $>0.05$ )

S6). The bovine catalase-positive control produced a bright band on the catalase activity gel (Fig. 1C) but did not show on the Coomassie-stained gel (Supplemental Data, Fig. S6) likely due to the low amount loaded $(0.26 \mathrm{ng})$ being below the detection limit. E. coli KatG is $320 \mathrm{kDa}$ whilst KatE is $336 \mathrm{kDa}$ with the theoretical $\mathrm{pI}$ calculated from uniprot being 5.14 for KatG and 5.54 for KatE. As these values are close, KatE and KatG are likely to migrate to a similar point on the native PAGE gel. E.coli KatG has previously been shown to migrate further into a native-PAGE gel than KatE (Dong et al. 2009) which would be expected due to the lower molecular weight and lower pI. The brighter band 
is likely therefore to be KatE whilst the duller band below is likely to be KatG. A clear increase in KatE/KatG activity is seen when exposed to exposure to $\mathrm{H}_{2} \mathrm{O}_{2}(0.1 \mathrm{mM})$. A small increase in catalase activity is also seen in the $100 \mu \mathrm{g} /$ $\mathrm{mL}$ gentamicin-exposed samples compared to the $0 \mu \mathrm{g} / \mathrm{mL}$ gentamicin-exposed samples. However, analysis on the band intensities (Fig. 1D) again showed this to be not statistically significant (One-way ANOVA $(F(2,6)=376.8, P<0.0001$, Tukey's post hoc test $P=0.7776$ ).

\section{Dissipation of the proton motive force diminshes gentamicin lethality in aerobially-grown cells}

The effect of the PMF uncoupler DNP on gentamicin susceptibility was tested on aerobically grown E. coli EC958 cells. Exponentially growing cells were pre-exposed to $1 \mathrm{mM}$ DNP for $30 \mathrm{~min}$ before addition of varying gentamicin concentrations. The presence of DNP resulted in a significant decrease in gentamicin lethality (Fig. 2A). The $\mathrm{IC}_{50}$ value without DNP was $5 \mu \mathrm{g} / \mathrm{mL}$ which is consistent with the EUCAST MIC values for gentamicin and $E$. coli at $>4 \mathrm{mg} / \mathrm{L}$ (Jakobsen et al. 2007). The $\mathrm{IC}_{50}$ value with DNP was $45 \mu \mathrm{g} / \mathrm{mL}$ resulting in a 600 -fold $(3.15 \log 10)$ increase in $\%$ survival at $50 \mu \mathrm{g} / \mathrm{mL}$ gentamicin.

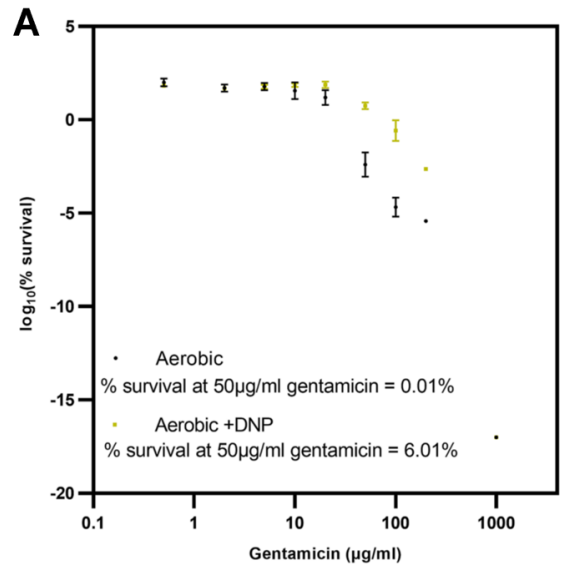

Fig. 2 Dissipation of the proton motive force leads to a significant decrease in gentamicin toxicity A E. coli EC958 cells grown aerobically in M9 minimal media supplemented with $0.1 \%$ casamino acids were exposed to $\pm 1 \mathrm{mM}$ DNP for $30 \mathrm{~min}$ followed by incubation with varying concentrations of gentamicin for $90 \mathrm{~min}$. This was followed by serial dilutions, spotting on LB agar and overnight incubation at $37{ }^{\circ} \mathrm{C}$ to enumerate $\mathrm{CFU} / \mathrm{mL}$. Mean \% survival values are shown \pm standard deviation from 2 biological repeats each with 3 technical repeats. B E. coli EC958 cells grown aerobically in M9 minimal media supplemented with $0.1 \%$ casamino acids were
To confirm that DNP is indeed dissipating the PMF, a fluorescent voltage-sensitive dye $\operatorname{DiSC}_{3}(5)$ was used to measure the electrical component of the PMF: $\mathrm{DiSC}_{3}(5)$ associates with the negatively charged inner membrane when the PMF is high, and is released upon membrane depolarization resulting in an increase in fluorescence (te Winkel et al. 2016). E. coli EC958 ST131 was again preexposed to $1 \mathrm{mM}$ DNP for $30 \mathrm{~min}$ before PMF quantitation with $\operatorname{DiSC}_{3}(5)$, and a positive control was performed for 'cells without DNP' (Fig. 2B). A negative control was performed without cells or DNP (i.e. buffer only) to measure the maximum fluorescence of the free dye. A clear increase in fluorescence is observed of approximately twofold between cells exposed to DNP and those not exposed to DNP. Since the NO-donor GSNO, a respiratory inhibitor, has previously been shown to provide resistance to gentamicin in the pathogenic E. coli EC958 ST131 strain (Ribeiro et al. 2021), it was also of interest to confirm that GSNO can dissipate the PMF, which indeed it can (Supplemental data, Fig. S2).

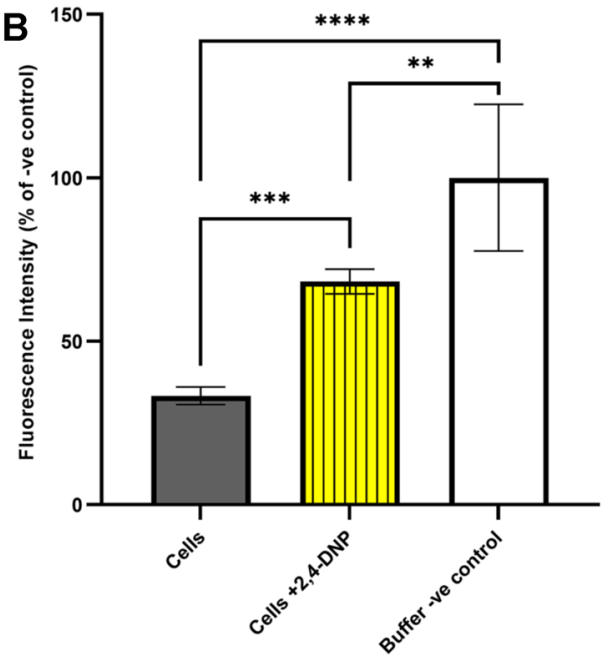

exposed to $\pm 1 \mathrm{mM}$ DNP for $30 \mathrm{~min}$. Cells were harvested and the electrical potential of the $\mathrm{PMF}$ was measured with a plate reader using the fluorescent dye $\operatorname{DiSC}_{3}(5)(2 \mu \mathrm{M})$. Control experiments were performed without DNP and without cells (i.e. buffer only). Data in the figure are at time point $2452 \mathrm{~s}$ and are averages of six repeats including two biological repeats for each condition. Data expressed as $\%$ relative to the negative control. (One-way ANOVA with Tukey's post hoc tests: $* * * * P$ value $<0.0001, * * * P$ value $<0.001, * * P$ value $<0.01)$ 


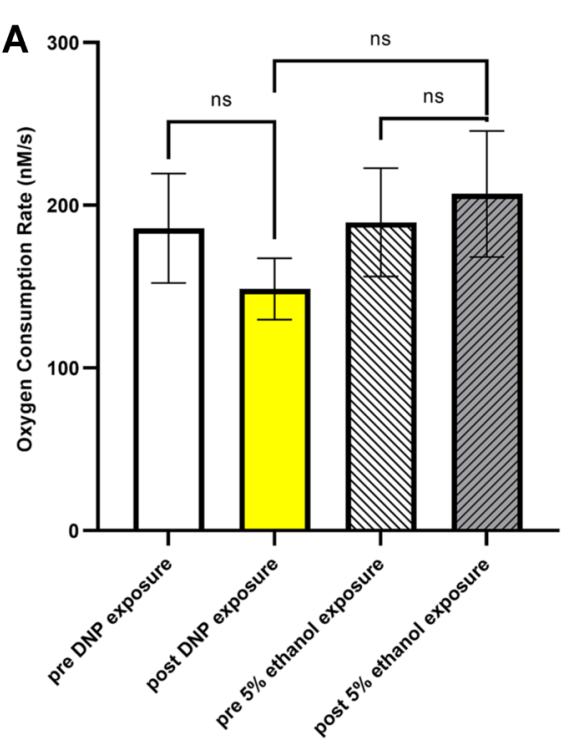

Fig. 3 Dissipation of the proton motive force does not alter respiratory oxygen consumption but increases ROS. A Suspensions of $4.8 \times 10^{8} \mathrm{CFU} / \mathrm{mL}$ of $E$. coli $\mathrm{EC} 958$ grown aerobically were diluted into fresh $\mathrm{M} 9$ minimal medium supplemented with $0.1 \%$ casamino acids to $8.0 \times 10^{7} \mathrm{CFU} / \mathrm{mL}$ in the Rank Brothers Clark oxygen electrode chamber after a baseline of 5 min was recorded. Voltage data were collected for $8 \mathrm{~min}$ followed by the addition of the plunger to exclude external oxygen and data were recorded for another $10 \mathrm{~min}$. DNP (1 mM final) was injected and data recorded until all oxygen was consumed. Since, DNP was dissolved in ethanol, control experi-

\section{The uncoupler DNP does not alter respiratory oxygen consumption but results in an increase in ROS production}

The influence of $1 \mathrm{mM}$ DNP upon the respiration rate of E. coli EC958 was measured via monitoring oxygen consumption in an oxygen electrode (Fig. 3A, Supplemental Data Fig. S3). A minor decrease in oxygen consumption of aerobically grown cells was observed in response to $1 \mathrm{mM}$ DNP that is not statistically significant (One-way ANOVA $(F(3,8)=1.76, P=0.2322)$. An ethanol control was also performed as DNP was solubilised in this solvent, which elicited a small rise in oxygen consumption that was not statistically significant. (One-way ANOVA $(F(3,8)=1.76$, $P=0.2322)$ ).

The influence of the alternative more potent uncoupler FCCP upon the respiration rate of E. coli EC958 was also studied (Supplementary data Fig. S5). At $10 \mu \mathrm{M}$, only a minor increase in the respiration rate was seen that is not statistically significant (unpaired t test $P=0.7871$ ).

Interestingly, DNP treatment produced a noticeable increase in catalase activity (Fig. 3B) indicating that DNP is promoting the production of ROS species (One-way ANOVA $(F(3,7)=734.9, P<0.0001$, Tukey's post hoc test $P<0.0001)$. The ethanol control also resulted in an increase

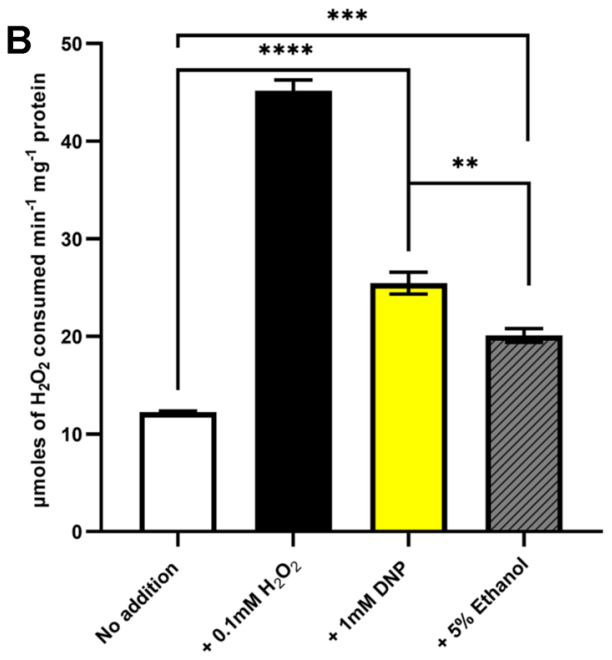

ments were performed with this solvent. (One-way ANOVA with Tukey's post hoc tests: n.s (not significant): $P$ value $>0.05$ ). B Suspensions of $1.6 \times 10^{8}$ cells $/ \mathrm{ml}$ of $E$. coli EC958 grown in M9 minimal medium supplemented with $0.1 \%$ casamino acids were exposed to a sub-lethal level of hydrogen peroxide $(0.1 \mathrm{mM}), \pm 1 \mathrm{mM}$ DNP or $5 \%$ ethanol for $30 \mathrm{~min}$. Cells were then washed, cell debris was removed and catalase activity was measured in the cell-free extract. (One-way ANOVA with Tukey's post hoc tests: $* * * * P$ value $<0.0001$, ***P value $<0.001, * * P$ value $<0.01)$

in catalase activity, although DNP exposure did result in a statistically significant increase in catalase activity compared to this control [One-way ANOVA $(F(3,7)=734.9$, $P<0.0001$, Tukey's post hoc test $P=0.0013)]$.

\section{Dissipation of the proton motive force diminishes gentamicin lethality in anaerobically grown cells}

As demonstrated above, dissipation of the PMF by DNP under aerobic conditions diminishes gentamicin lethality (Fig. 2A), and this effect was not due to alleviation of ROS production by DNP (Fig. 3B): indeed, quite the opposite. To analyse the effects of DNP-mediated PMF disruption upon gentamicin lethality in isolation from ROS, viability assays were performed under anaerobic conditions (i.e. where ROS production by the respiratory chain is excluded). To ensure that cells were performing anaerobic respiration, control experiments were performed in the absence of exogenous electron acceptors which abolished growth (Supplemental Data, Fig. S4). Pre-exposure of E. coli to $1 \mathrm{mM}$ DNP for $30 \mathrm{~min}$ at $\mathrm{OD}_{600}=0.1$ prior to addition of varying gentamicin concentrations resulted in a large decrease in gentamicin lethality (Fig. 4). The change in $\mathrm{IC}_{50}$ value resulting 


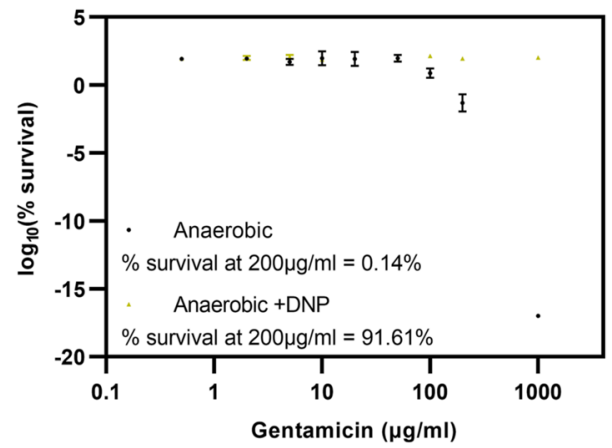

Fig. 4 The uncoupler DNP elicits a decrease in gentamicin toxicity under anaerobic conditions. E. coli EC958 cells grown anaerobically in M9 minimal media supplemented with $0.1 \%$ casamino acids $(\mathrm{w} / \mathrm{v}), 100 \mathrm{mM}$ sodium nitrate and $0.2 \%$ glycerol $(\mathrm{v} / \mathrm{v})$ were exposed to $\pm 1 \mathrm{mM}$ DNP for $30 \mathrm{~min}$ followed by incubation with varying concentrations of gentamicin for $90 \mathrm{~min}$. This was followed by serial dilutions, spotting on LB-agar and overnight incubation at $37{ }^{\circ} \mathrm{C}$ to enumerate $\mathrm{CFU} / \mathrm{mL}$. Mean \% survival values are shown \pm standard deviation from 2 biological repeats each with 3 technical repeats

from DNP exposure could not be quantified due to the complete abolition of gentamicin toxicity by DNP, although it was noted that in the absence of DNP gentamicin toxicity was diminished $\left(\mathrm{IC}_{50}=91.19 \mu \mathrm{g} / \mathrm{mL}\right)$ compared to aerobic growth $\left(\mathrm{IC}_{50}=5 \mu \mathrm{g} / \mathrm{mL}\right.$, Fig. $\left.2 \mathrm{~A}\right)$. This might suggest a role for anaerobic respiratory complexes in gentamicin lethality, although this is speculative at this stage and will require further work to investigate this hypothesis.

\section{Discussion}

It is well-known that respiratory activity can promote the lethality of many antibiotics, and there is unequivocal evidence to support the role of ROS generation by the aerobic respiratory chain in the lethality of a number of different antibiotic classes (reviewed in (Stokes et al. 2019)). However, the interplay between ROS, respiratory activity and aminoglycoside lethality has remained less clear, and the maintenance of PMF provides an alternative mechanism for the respiratory chain to potentiate the lethality of aminoglycosides (i.e. via promoting the uptake of positively charged aminoglycosides). Hence, the current study sought to investigate the competing ROS vs. PMF hypotheses under comparable conditions to assess the underpinning mechanism for gentamicin lethality for a clinically-relevant $E$. coli strain. The first question to answer was: does exposure of $E$. coli to gentamicin result in the production of ROS? To answer this simple question, the three approaches of a catalase assay, direct ROS measurement and a native PAGE KatE/KatG catalase assay were undertaken and all approaches demonstrated that gentamicin exposure does not result in a significant increase in ROS under the conditions tested (Fig. 1).
It has previously been shown that the 30 min exposure to $0.1 \mathrm{mM} \mathrm{H}_{2} \mathrm{O}_{2}$ used in this investigation can upregulate $E$. coli KatG and increase survivability against oxidative stress (Rodríguez-Rojas et al. 2020). The experiments were performed over a concentration range that is known to be toxic to this strain under the conditions tested and provides very good evidence to support the hypothesis that lethal doses of gentamicin do not elicit significant increases in ROS. The small increase in ROS production seen in the direct ROS measurements (Fig. 1B) could be due to the detection of superoxide that the $2^{\prime}, 7^{\prime}$-dichlorodihydrofluorescein diacetate-based fluorescent dye can detect (Freemerman et al. 2014) as opposed to the catalase assays being specific for $\mathrm{H}_{2} \mathrm{O}_{2}$ detection.

The respiratory uncoupler DNP has been previously used to demonstrate that dissipation of the PMF significantly diminishes the lethality of the aminoglycoside dihydrostreptomycin (Campbell and Kadner 1980). To verify that this is the case under the same conditions that ROS species were measured, aerobically grown $E$. coli EC958 was exposed to $1 \mathrm{mM}$ DNP over a range of gentamicin concentrations and viable counts were measured. These data confirm that DNP elicits a significant decrease in gentamicin lethality (Fig. 2A), consistent with the hypothesis that maintenance of the PMF by respiratory activity potentiates the bactericidal effects of gentamicin. To further investigate this, $1 \mathrm{mM}$ DNP was confirmed to dissipate the electrical potential of the inner membrane as expected (Fig. 2B). Since the respiratory inhibitor and NO-donor GSNO has previously been shown to diminish gentamicin lethality (Ribeiro et al. 2021), it was of interest to investigate the hypothesis that exposure to GSNO could dissipate the PMF. This was tested under the conditions used in this previous study, and a significant dissipation of the membrane electrical potential was observed in response to GSNO (Supplemental Data, Fig. S2), a magnitude change comparable to that of $1 \mathrm{mM}$ DNP. Significant effort was made to investigate whether GSNO elevated ROS production using the fluorescent dye approach described herein, but the background fluorescence generated by GSNO was far too high to generate reliable and reproducible results. Furthermore, the catalase assay could not be used as this enzyme utilises a haem cofactor and is well-known to be inhibited by NO (Titov and Osipov 2017). Nevertheless, transcriptomics studies have been undertaken where $E$. coli was exposed to GSNO and no perturbations in ROS stress responses were detected (Flatley et al. 2005). Taken together with the data described herein, this supports the hypothesis that inhibition of aerobic respiration by GSNO diminishes the lethality of gentamicin through dissipation of the PMF and not alleviation of ROS generation by the respiratory chain. Indeed, our observations are consistent with previous work on Salmonella where NO-mediated 
respiratory inhibition diminished the toxicity of aminoglycosides through a mechanism involving diminished gentamicin uptake (McCollister et al. 2011).

It has previously been reported that protonophores, such as FCCP and DNP, can block translocation of periplasmic and membrane proteins in E. coli leading to aggregation and induced heat shock response with an increased level of the heat shock regulator protein sigma-32 (Jana et al. 2009). The heat shock protease ClpP is implicated in this process (Jana et al. 2009) and upregulation of the heat shock proteases has been linked to increased resistance to antimicrobial stress in Acinetobacter baumannii (Lazaretti et al. 2020)(Cardoso et al. 2010) and E.coli (Yamaguchi et al. 2003)((Kohanski et al. 2008). DNP has previously been shown to upregulate several heat shock responses in E. coli (Gage and Neidhardt 1993), so it is important to consider that DNP-induced stress response may contribute to the DNP-mediated increases in resistance to gentamicin observed herein (Figs. 2A and 4). However, the well-characterised uncoupling action (and resulting diminished aminoglycoside uptake) seems a more probably explanation for the DNP-mediated decrease in gentamicin lethality.

To further investigate potential influences in oxygen utilisation by DNP, oxygen electrode experiments were performed. These data demonstrate that DNP did not elicit any significant change in respiratory oxygen consumption at $1 \mathrm{mM}$ (Fig. 3A), which is consistent with previous studies using $1 \mathrm{mM}$ DNP (Goto and Anraku 1974) as DNP is a protonophore that allows protons to leak across the normally proton-impermeable cytoplasmic membrane inhibiting PMF-dependent transport systems such as gentamicin uptake with little effect on the cellular respiration (Taber et al. 1987). As a control, the more potent uncoupler FCCP also did not show any significant change in oxygen consumption at $10 \mu \mathrm{M}$ (Supplemental Data, Fig. S5). We acknowledge that for these experiments cells were exposed to uncouplers for slightly less time than the $30 \mathrm{~min}$ preexposures used for some other figures, although we do not anticipate that a marginal increase in exposure time would elicit an increase in oxygen consumption. It was interesting to observe an increase in catalase activity in cells that were exposed to DNP, especially as DNP protects the cells against gentamicin lethality (Fig. 2A). Two explanations therefore present themselves: i) The effects of DNP-mediated increase in ROS upon cell survival are insignificant compared to the DNP-mediated decrease in PMF that protect $E$. coli from gentamicin uptake ROS are not; ii) pre-exposure to DNP activates the ROS stress-response systems and renders the cells more tolerant to gentamicin-mediated ROS toxicity possibly through upregulation of KatE and KatG. However, given that gentamicin does not elicit the formation of significant levels of ROS in this study (Fig. 1), it is more likely that the protective effects of DNP-mediated membrane depolarisation (Fig. 2B) outweigh any toxicity issues resulting from elevated ROS due to DNP.

Finally, as aminoglycoside antibiotics work on E. coli grown under anaerobic conditions, it is logical to hypothesise that DNP will also diminish the lethality of gentamicin under these conditions. To test this hypothesis, EC958 was grown under anaerobic conditions and viability assays were performed following pre-exposure to $1 \mathrm{mM} \mathrm{DNP}$ followed by addition of various concentrations of gentamicin (Fig. 4). These data support the hypothesis that dissipation of the PMF by DNP can abolish the lethality of gentamicin under conditions that exclude the possibility of ROS generation by the respiratory chain. This further supports the hypothesis that DNP diminishes the lethality of gentamicin through dissipation of the PMF and not alleviation of ROS generation by the respiratory chain.

Supplementary Information The online version contains supplementary material available at https://doi.org/10.1007/s00203-021-02710-y.

Acknowledgements We thank Edith Blackburn and Tanya Knight (University of Kent) for help with the FACS analyses and thank the Kent Fungal Group for access to the FLUOstar Omega plate reader.

Author contributions CMW was involved in planning and performing the majority of experiments and wrote the paper, AMW contributed to the flow cytometer work, SF performed the PMF work, LGH performed the gentamicin viability work, GKR contributed to microbiological experimental design and data analysis, and MS was responsible for experimental design, data analysis and wrote the paper.

Funding This work was supported by a VC PhD studentship (University of Kent).

\section{Declarations}

Conflict of interest The authors declare that there is no conflict of interest.

Ethical approval No ethical approval was required.

Open Access This article is licensed under a Creative Commons Attribution 4.0 International License, which permits use, sharing, adaptation, distribution and reproduction in any medium or format, as long as you give appropriate credit to the original author(s) and the source, provide a link to the Creative Commons licence, and indicate if changes were made. The images or other third party material in this article are included in the article's Creative Commons licence, unless indicated otherwise in a credit line to the material. If material is not included in the article's Creative Commons licence and your intended use is not permitted by statutory regulation or exceeds the permitted use, you will need to obtain permission directly from the copyright holder. To view a copy of this licence, visit http://creativecommons.org/licenses/by/4.0/. 


\section{References}

Anderson MD, Prasad TK, Stewart CR (1995) Changes in isozyme profiles of catalase, peroxidase, and glutathione reductase during acclimation to chilling in mesocotyls of maize seedlings. Plant Physiol 109:1247-1257. https://doi.org/10.1104/pp.109.4.1247

Campbell BD, Kadner RJ (1980) Relation of aerobiosis and ionic strength to the uptake of dihydrostreptomycin in Escherichia coli. Biochim Biophys Acta 593:1-10. https://doi.org/10.1016/ 0005-2728(80)90002-X

Cardoso K, Gandra RF, Wisniewski ES et al (2010) DnaK and GroEL are induced in response to antibiotic and heat shock in Acinetobacter baumannii. J Med Microbiol 59:1061-1068. https://doi. org/10.1099/jmm.0.020339-0

Croxall G, Hale J, Weston V et al (2011) Molecular epidemiology of extraintestinal pathogenic Escherichia coli isolates from a regional cohort of elderly patients highlights the prevalence of ST131 strains with increased antimicrobial resistance in both community and hospital care setting. J Antimicrob Chemother 66:2501-2508

Davis BD (1987) Mechanism of bactericidal action of aminoglycosides. Microbiol Rev 51:341-350. https://doi.org/10.1128/mmbr. 51.3.341-350.1987

Davis BD, Chen L, Tai PC (1986) Misread protein creates membrane channels: An essential step in the bactericidal action of aminoglycosides. Proc Natl Acad Sci USA 83:6164-6168. https://doi.org/ 10.1073/pnas.83.16.6164

Dong T, Chiang SM, Joyce C et al (2009) Polymorphism and selection of rpoS in pathogenic Escherichia coli. BMC Microbiol 9:1-13. https://doi.org/10.1186/1471-2180-9-118

Dwyer DJ, Kohanski MA, Hayete B, Collins JJ (2007) Gyrase inhibitors induce an oxidative damage cellular death pathway in Escherichia coli. Mol Syst Biol. https://doi.org/10.1038/msb4100135

Dwyer DJ, Belenky PA, Yang JH et al (2014) Antibiotics induce redoxrelated physiological alterations as part of their lethality. Proc Natl Acad Sci USA 111:E2100-E2109

Farha MA, Verschoor CP, Bowdish D, Brown ED (2013) Collapsing the proton motive force to identify synergistic combinations against Staphylococcus aureus. Chem Biol 20:1168-1178. https:// doi.org/10.1016/j.chembiol.2013.07.006

Flatley J, Barrett J, Pullan ST et al (2005) Transcriptional responses of Escherichia coli to $S$-Nitrosoglutathione under defined chemostat conditions reveal major changes in methionine biosynthesis. J Biol Chem 280:10065-10072

Forde BM, Ben Zakour NL, Stanton-Cook M et al (2014) The complete genome sequence of Escherichia coli EC958: a high quality reference sequence for the globally disseminated multidrug resistant $E$. coli $\mathrm{O} 25 \mathrm{~b}: \mathrm{H} 4-\mathrm{ST} 131$ clone. PLoS ONE 9:e104400

Foti JJ, Devadoss B, Winkler JA et al (2012) Oxidation of the guanine nucleotide pool underlies Cell Death by Bactericidal Antibiotics. Science 80-(336):315-319. https://doi.org/10.1126/science. 1219192

Freemerman AJ, Johnson AR, Sacks GN et al (2014) Metabolic reprogramming of macrophages: glucose transporter 1 (GLUT1)-mediated glucose metabolism drives a proinflammatory phenotype. J Biol Chem 289:7884-7896. https://doi.org/10.1074/jbc.M113. 522037

Gage DJ, Neidhardt FC (1993) Adaptation of Escherichia coli to the uncoupler of oxidative phosphorylation 2,4-dinitrophenol. J Bacteriol 175:7105-7108. https://doi.org/10.1128/jb.175.21.71057108.1993

Gilberthorpe NJ, Poole RK (2008) Nitric oxide homeostasis in Salmonella Typhimurium: roles of respiratory nitrate reductase and flavohemoglobin. J Biol Chem 283:11146-11154
Goto F, Anraku Y (1974) Studies on the active transport reaction in sodium azide- and 2,4-dinitrophenol-sensitive mutants of Escherichia coli. J Biochem 75:243-251

Hillar A, Van CL, Loewen PC (1999) Intracellular location of catalaseperoxidase hydroperoxidase I of Escherichia coli. FEMS Microbiol Lett 170:307-312

Imlay JA, Fridovich I (1991) Superoxide production by respiring membranes of Escherichia coli. Free Radic Res Commun 12-3:59-66. https://doi.org/10.3109/10715769109145768

Jakobsen L, Sandvang D, Jensen VF et al (2007) Gentamicin susceptibility in Escherichia coli related to the genetic background: problems with breakpoints. Clin Microbiol Infect 13:830-832. https:// doi.org/10.1111/j.1469-0691.2007.01751.x

Jana B, Panja S, Saha S, Basu T (2009) Mechanism of protonophoresmediated induction of heat-shock response in Escherichia coli. BMC Microbiol 9:1-9. https://doi.org/10.1186/1471-2180-9-20

Keyer K, Imlay JA (1996) Superoxide accelerates DNA damage by elevating free-iron levels. Proc Natl Acad Sci USA 93:13635-13640. https://doi.org/10.1073/pnas.93.24.13635

Kohanski MA, Dwyer DJ, Hayete B et al (2007) A common mechanism of cellular death induced by bactericidal antibiotics. Cell 130:797-810. https://doi.org/10.1016/j.cell.2007.06.049

Kohanski MA, Dwyer DJ, Wierzbowski J et al (2008) Mistranslation of membrane proteins and two-component system activation trigger antibiotic-mediated cell death. Cell 135:679-690. https://doi.org/10.1016/j.cell.2008.09.038

Kohanski MA, Dwyer DJ, Collins JJ (2010) How antibiotics kill bacteria: from targets to networks. Nat Rev Microbiol 8:423-435

Kumar SR, Imlay JA (2013) How Escherichia coli tolerates profuse hydrogen peroxide formation by a catabolic pathway. J Bacteriol 195:4569-4579. https://doi.org/10.1128/JB.00737-13

Lazaretti WY, dos Santos EL, da Conceição Silva JL et al (2020) Upregulation of the $\operatorname{clp} B$ gene in response to heat shock and beta-lactam antibiotics in Acinetobacter baumannii. Mol Biol Rep 47:1499-1505. https://doi.org/10.1007/ s11033-019-05209-4

Lewis K, Naroditskaya V, Ferrante A, Fokina I (1994) Bacterial resistance to uncouplers. J Bioenerg Biomembr 26:639-646. https://doi. org/10.1007/BF00831539

Lobritz MA, Belenky P, Porter CBM et al (2015) Antibiotic efficacy is linked to bacterial cellular respiration. Proc Natl Acad Sci USA 112:8173-8180

Markwell MAK, Haas SM, Bieber LL, Tolbert NE (1978) Modification of Lowry procedure to simplify protein determination in membrane and lipoprotein samples. Anal Biochem 87:206-210

McBee ME, Chionh YH, Sharaf ML et al (2017) Production of superoxide in bacteria is stress- and cell state-dependent: a gating-optimized flow cytometry method that minimizes ROS measurement artifacts with fluorescent dyes. Front Microbiol 8:1-17. https:// doi.org/10.3389/fmicb.2017.00459

McCollister BD, Hoffman M, Husain M, Vazquez-Torres A (2011) Nitric oxide protects bacteria from aminoglycosides by blocking the energy-dependent phases of drug uptake. Antimicrob Agents Chemother 55:2189-2196

Nicolas-Chanoine M-H, Blanco J, Leflon-Guibout V et al (2008) Intercontinental emergence of Escherichia coli clone O25: H4-ST131 producing CTX-M-15. J Antimicrob Chemother 61:273-281. https://doi.org/10.1093/jac/dkm464

Pezzoni M, Pizarro R, Costa C (2018) Detection of catalase activity by polyacrylamide gel electrophoresis (PAGE) in cell extracts from Pseudomonas aeruginosa. Bio-Protoc 8:1-13. https://doi.org/10. 21769/bioprotoc. 2869

Ribeiro CA, Rahman LA, Holmes LG et al (2021) Nitric oxide (NO) elicits aminoglycoside tolerance in Escherichia coli but antibiotic resistance gene carriage and NO sensitivity have not 
co-evolved. Arch Microbiol 203:2541-2550. https://doi.org/10. 1007/s00203-021-02245-2

Rodríguez-Rojas A, Kim JJ, Johnston PR, et al (2020) Non-lethal exposure to $\mathrm{H}_{2} \mathrm{O}_{2}$ boosts bacterial survival and evolvability against oxidative stress

Shepherd M, Sanguinetti G, Cook GM, Poole RK (2010) Compensations for diminished terminal oxidase activity in Escherichia coli: cytochrome $b d$-II-mediated respiration and glutamate metabolism. J Biol Chem 285:18464-18472

Stokes JM, Lopatkin AJ, Lobritz MA, Collins JJ (2019) Bacterial metabolism and antibiotic efficacy. Cell Metab 30:251-259. https://doi.org/10.1016/j.cmet.2019.06.009

Taber HW, Mueller JP, Miller PF, Arrow AS (1987) Bacterial uptake of aminoglycoside antibiotics. Microbiol Rev 51:439-457

te Winkel JD, Gray DA, Seistrup KH et al (2016) Analysis of antimicrobial-triggered membrane depolarization using voltage sensitive dyes. Front Cell Dev Biol 4:1-10. https://doi.org/10.3389/fcell. 2016.00029
Titov VY, Osipov AN (2017) Nitrite and nitroso compounds can serve as specific catalase inhibitors. Redox Rep 22:91-97. https://doi. org/10.1080/13510002.2016.1168589

Totsika M, Beatson SA, Sarkar S et al (2011) Insights into a multidrugresistant Escherichia coli pathogen of the globally disseminated ST131 lineage: genome analysis and virulence mechanisms. PLoS ONE 6:e26578

Yamaguchi Y, Tomoyasu T, Takaya A et al (2003) Effects of disruption of heat shock genes on susceptibility of Escherichia coli to fluoroquinolones. BMC Microbiol 3:1-8. https://doi.org/10.1186/ 1471-2180-3-16

Publisher's Note Springer Nature remains neutral with regard to jurisdictional claims in published maps and institutional affiliations. 